Original article

\title{
Preoperative Hba1c level in prediction of short-term morbidity and mortality outcomes following coronary artery bypass grafting surgery
}

\author{
Ümit Arslan ${ }^{1}$, Mehmet Erdem Memetoğlu ${ }^{2}$, Rasim Kutlu ${ }^{3}$, Ozan Erbasan ${ }^{4}$, Mehmet Tort ${ }^{1}$, Eyüp Serhat Çalık ${ }^{1}$, \\ Ziya Yıldız ${ }^{1}$, M. Ali Kaygın ${ }^{1}$, Ozan Erdem ${ }^{4}$, Ali ìnsan Tekin ${ }^{4}$ \\ ${ }^{1}$ Atatürk Training and Education Hospital, Erzurum, Turkey \\ ${ }^{2}$ Dr. Siyami Ersek Cardiovascular and Thoracic Surgery Hospital, İstanbul, Turkey \\ ${ }^{3}$ Denizli State Hospital, Denizli, Turkey \\ ${ }^{4}$ Akdeniz University School of Medicine, Antalya, Turkey
}

Received 17 March 2015, Accepted 20 March 2015

(C) 2015, Arslan U., Memetoğlu M.E., Kutlu R., Erbasan O., Tort M., Çalık E.S., Yıldız Z., Kaygın M.A., Erdem O., Tekin A.I.

(C) 2015, Russian Open Medical Journal

Abstract: Objective - This study was conducted to determine whether $\mathrm{HbA} 1 \mathrm{c}$ is a predictor of short term mortality and morbidity after coronary artery bypass graft operation.

Methods - The coronary artery bypass graft operation was performed on the patients between January 2009 and January 2013. Each patient's medical record was retrospectively reviewed. The patients who were included in the study were evaluated in groups of 60 . One group was comprised of nondiabetic patients, whose $\mathrm{HbA1c}$ level is below $6 \%$ (the control group 0 ), the other included diabetic patients with the HbA1c level is between $6-6.9 \%$ (the group 1 ) and the last group, group 2, included those patients with $\mathrm{HbA1c}$ level is equal or greater than $7 \%$. Pre, peri and post operation data was compared. The deaths that occured in the first 30 days were evaluated as mortality and complications as morbitity.

Results - While mortality was not observed in the control group, one incident was observed in group 1 and 5 in group 2, which corresponds to $1.7 \%$ and $8.3 \%$ respectively. The mortality ratio in the group with patients whose HbA1c was greater or equal to $7 \%$ found statistically significant compared to the control group $(P=0.02)$. The following parameters were observed in group 2 and were found statistically significant: the need for dialisis $(25 \%, \mathrm{P}<0.01)$, atrial fibrillation $(33 \%, \mathrm{P}=0.01)$, revision due to bleeding $(10 \%, \mathrm{P}=0.18)$, cerebrovascular event $(16,7 \%, P=0.01)$, duration of mechanic ventilation $(19.5 \pm 21.6, P=0.06)$, duration of hospital stay (approximately $9.91 \pm 5.35$ days, $\mathrm{P}=0.01)$, infection in $\mathrm{scar}(53 \%, \mathrm{P}<0.01)$, mediastenit $(11 \%, \mathrm{P}=0.01)$ and urinary tract infection $(10 \%, \mathrm{P}=0.01)$

Conclusion - We concluded that in those diabetic patients that elective coronart artery bypass graft is applied, highly reactive HbA1c levels $(\mathrm{HbA} 1 \mathrm{c} \geq 7)$, may indicate morbitity in the early stages of post operation.

Keywords: diabetes mellitus, HbA1c, coronary artery bypass operation, morbidity, mortality

Cite as Arslan U, Memetoğlu ME, Kutlu R, Erbasan O, Tort M, Çalık ES, Yıldız Z, Kaygın MA, Erdem O, Tekin Al. Preoperative Hba1c level in prediction of shortterm morbidity and mortality outcomes following coronary artery bypass grafting surgery. Russian Open Medical Journal 2015; 4: e0204.

Correspondence to Mehmet Erdem Memetoğlu. Address: Dr.Siyami Ersek Cardiovascular and Thoracic Surgery Hospital, Cardiovascular Surgery Department, İstanbul, Turkey. Phone: 021654244 44. Fax: 021634893 25. E-mail: dr.m.erdem07@hotmail.com

\section{Introduction}

Diabetes mellitus (DM) is an established risk factor for the development of coronary artery disease (CAD) and approximately $20 \%$ to $30 \%$ of the patients undergoing coronary artery bypass graft operation (CABG) have DM [1]. The morbitity and mortality levels of diabetic patients increased by 5-10 fold in post operation stage [2].

Blood glucose levels regulate the glycosylation process of red blood cells. Given the lifespan of red blood cells, (90 to 120 days), continuous cell turnover and fluctuating glucose levels lead to a portion of $\mathrm{HbA} 1 \mathrm{c}$ (normal range 4.0-5.9\%) within the blood being glycosylated. Thus a measurement of the percentage of glycosylated hemoglobin complexes would be indicative of the patient's glucose levels over the previous 3 to 4 months. This is substantially more informative than a single blood glucose reading which is very labile and dependent on shortterm changes in diet and metabolic demands. As such, it has been deemed the gold standard for monitoring diabetic control [3].

It is shown that $\mathrm{HbA1c}$ levels, morbitiy and mortality rates are closely related in the patients that CABG is applied [4]. Recently, a small number of studies have called into question the predictive value of $\mathrm{HbA1C}$ on short-term outcomes in well-controlled diabetes [5].

The purpose of this study was to determine whether $\mathrm{HbA} 1 \mathrm{C}$ could predict probable adverse events including early postoperative complications in the surgical intensive care unit (ICU) and in-hospital mortality after CABG surgery in patients with well ( $\mathrm{HbA} 1 \mathrm{c}<7)$, poorly $(\mathrm{HbA} 1 \mathrm{c} \geq 7$ ) controlled $\mathrm{HbA} 1 \mathrm{c}$ patients, and case-matched nondiabetic (ND) patients. 
Table 1. Demographic and preoperative data of the patients

\begin{tabular}{|c|c|c|c|c|}
\hline Parameters & Group $1(n=60)$ & Group $2(n=60)$ & Group $0(n=60)$ & $P$-value $\neq$ \\
\hline Age, years & $62.80 \pm 7.90$ & $61.50 \pm 7.40$ & $62.90 \pm 7.50$ & 0.61 \\
\hline Female gender, n (\%) & $15(25.0)$ & $24(40.0)$ & $16(26.7)$ & 0.15 \\
\hline $\mathrm{BMI}, \mathrm{kg} / \mathrm{m}^{2}$ & $28.40 \pm 4.30$ & $28.50 \pm 3.40$ & $29.10 \pm 3.70$ & 0.38 \\
\hline Hypertension, n (\%) & $31(51.7)$ & $42(70.0)$ & $28(46.7)$ & 0.01 \\
\hline USAP, n (\%) & $14(23.3)$ & $22(36.7)$ & $6(10.0)$ & 0.02 \\
\hline MI, n (\%) & $16(26.7)$ & $21(35)$ & $16(26.7)$ & 0.31 \\
\hline PAD, n (\%) & $10(16.7)$ & $14(23.3)$ & $1(1.7)$ & 0.01 \\
\hline CVA, n (\%) & $3(5.0)$ & $6(10.0)$ & $4(6.7)$ & 0.48 \\
\hline$E F, \%$ & $56.40 \pm 8.30$ & $56.90 \pm 7.90$ & $59.00 \pm 6.70$ & 0.15 \\
\hline FBG, $\mathrm{mg} / \mathrm{dl}$ & $143.00 \pm 39.70$ & $213.20 \pm 67.40$ & $92.10 \pm 14.00$ & $<0.01$ \\
\hline $\mathrm{Hb}, \mathrm{gr} / \mathrm{dl}$ & $13.50 \pm 1.40$ & $13.10 \pm 1.03$ & $13.60 \pm 1.10$ & 0.23 \\
\hline Creatinin, mg/dL & $0.87 \pm 0.20$ & $0.93 \pm 0.27$ & $0.88 \pm 0.10$ & 0.37 \\
\hline $\mathrm{LDL}, \mathrm{mg} / \mathrm{dL}$ & $113.0 \pm 35.0$ & $129.1 \pm 45.2$ & $112.4 \pm 29.6$ & 0.02 \\
\hline HbA1c, n (\%) & $6.40 \pm 0.27$ & $9.30 \pm 1.63$ & $5.50 \pm 0.26$ & $<0.01$ \\
\hline Need for inotropic support, $\mathrm{n}(\%)^{*}$ & $0(0)$ & $2(3.3)$ & $0(0)$ & 0.08 \\
\hline Duration of Diabetes, years & $8.18 \pm 5.60$ & $12.70 \pm 7.23$ & 0 & $<0.01$ \\
\hline
\end{tabular}

* patients who were followed in intensive care preoperatively and who need positive inotropic support.

$\neq \mathrm{p}$-value is determined by the comparison of the three groups.

$\mathrm{BMI}$, body mass index; USAP, unstable angina pectoris; MI, myocardial infarction; PAD, periferal artery disease; CVA, cerebrovascular accident; EF, ejection fraction; FBG, fasting blood glıcose level; Hb, hemoglobin; LDL, low density lipoprotein.

\section{Material and Methods}

The study was approved by the local ethics committee. The files containing information about 980 patients that CABG had been applied between January 2009 - January 2013 were retrospectively analyzed. The data of inbound patients that required surgical operation was acquired from patients' records which contains the forms of preoperative anamnesis and physical findings.

Those patients with coronary artery diesase and coronary angiography and those who have been applied CABG in elective conditions as well as those patients whose glicolized hemoglabin (HbA1c) level was observed accepted into study. The patients with the following were not included in the study; Myocardial infarction that was had three weeks before the operation, urgent operation, cardiogenic shock, reoperation, left ventricular aneurysm reconstruction, CABG in beating heart, valve reconstruction or replacement, atrial fibrilation, renal failure and dialysis, those male patients with hemoglobin levels below $13 \mathrm{ml} / \mathrm{dl}$, and women with $12 \mathrm{mg} / \mathrm{dl}$ and those patients with unacceptable tyroid test results.

The performed anesthesia, surgery and cardiopulmonary perfusion (CPP) methods were the same for all of the patients included in this atudy. Patients were monitored by, electrocardiography, pulse oximetry, urine output, invasive arterial and central venous pressure. Standard general anesthesia was applied using propofol vecurony, fentanyl, sevoflurane and remifentanil. Membrane oxygenator and non-pulsatile roller pump were used for extracorporeal circulation and moderate hypothermia (rectal temperature $28-30 \circ \mathrm{C}$ ) at mean arterial blood pressure was maintained to be in the range $60-80 \mathrm{mmHg}$. Duration of cardiopulmonary bypass (CPB) and aortic cross-clamping (ACC) of the patients were evaluated in minutes.

After the end of CPB, intravenous infusion of noradrenaline, dobutamine and dopamine were applied to those patients with hemodynamic instability as positive inotropic support. Postoperatively the patients were evaluated in terms of their adherence adhere to the mechanical ventilation time (hour), the amount of drainage (cc), intensive care unit length of stay (days), postoperative hospitalization time (days).
As morbidity parameters; the need for revision, atrial fibrillation, and hemodialysis requirement, cerebrovascular accident, infection (wound, mediastinit, urinary tract infections and pneumonia), pleural effusion requiring drainage, and sternal dehiscence requiring repair were evaluated.

Patients enrolled in the study (180 patients) were classified as 60 nondiabetic patients with HbA1c levels below 6\% (control group or group 0), 60 patients with diabetes and $\mathrm{HbA1c}$ levels between 6.0 to $6.9 \%$ (Group 1) and 60 patients with diabetes and $\mathrm{HbA1c}$ levels $\geq 7 \%$ (Group 2) Demographics and preoperative data of the patients are shown in Table 1. Preoperative, perioperative and postoperative data were compared. In the postoperative period surgical site infection, mediastinit, urinary tract infections and pneumonia were considered as the infection parameters. The first deaths in the 30 days were considered as mortality and all complications were evaluated as morbidity.

\section{Statististics}

Chi-square and t-test were used for statisticalcomparison in each of the three groups. The comparison between groups was performed with Kruskal-Wallis test, and the comparison of data for the independent variables was performed by Mann-Whitney $U$ test and Wilcoxon W test. SPSS V.18 for Windows was used for statistical analysis. Results were shown as mean $\pm S D$, and for all comparisons $\mathrm{P}<0.05$ was considered significant.

Results

Demographic and preoperative data of the patients are shown in Table 1. In terms of laboratory values; each patient's fasting blood glucose (FBG) displayed considerable difference between Group 1 and Group $2(\mathrm{P}<0.01)$. LDL levels displayed considerable difference, between Group 1 and Group $2(P=0.02)$ and Group 2 and the control group $(P=0.04)$. The mean value of $\mathrm{HbA1C}$ in Group 1 was $0.27 \pm 6.40 \%$, while the average in group 2 was $9.30 \pm 1.63 \%$. The P-value for two groups was determined as $<0.01$. 
Table 2. The means of the standard EuroSCORE values and statistical values of patients

\begin{tabular}{lccc}
\hline Groups & EuroSCORE & & $P$-value (<0,05 significant) \\
\hline Group 0 & $2.70 \pm 1.70$ & Grup 0-1 & 0.29 \\
Group 1 & $3.28 \pm 2.52$ & Grup 0-2 & 0.02 \\
Group 2 & $4.06 \pm 2.46$ & Grup 1-2 & 0.96 \\
\hline
\end{tabular}

Table 3. Perioperative findings of the patients

\begin{tabular}{|c|c|c|c|c|}
\hline Variables & Group $1(n=60)$ & Group $2(n=60)$ & Group $0(n=60)$ & $P$-value $\neq$ \\
\hline Distal anastomosis, number & $3.01 \pm 0.62$ & $2.95 \pm 0.56$ & $2.88 \pm 0.61$ & 0.47 \\
\hline IMA, n (\%) & $60(100)$ & $59(98.3)$ & $60(100)$ & 0.98 \\
\hline Saphenous vein, $\mathrm{n}(\%)$ & $59(98.3)$ & $56(93.3)$ & $53(88.3)$ & 0.73 \\
\hline Radial artery, $\mathrm{n}(\%)$ & $31(51.7)$ & $25(41.7)$ & $29(48.3)$ & 0.55 \\
\hline CPB duration, minutes & $123.9 \pm 22.7$ & $130.5 \pm 29.6$ & $111.9 \pm 17.7$ & 0.32 \\
\hline ACC, minutes & $64.75 \pm 13.38$ & $69.21 \pm 17.38$ & $58.50 \pm 11.54$ & 0.26 \\
\hline IABP, n (\%) & $5(8.3)$ & $8(15)$ & $1(1.7)$ & 0.01 \\
\hline Need for inotropic support, n (\%) & $18(28.8)$ & $21(35)$ & $5(8.3)$ & 0.01 \\
\hline
\end{tabular}

IMA, internal mammarian artery; CPB, cardiopulmonary bypass; ACC, aortic cross clamp; IABP, intraaortic balon pump.

$\neq \mathrm{p}$-value is determined by the comparison of the three groups.

Table 4. Comparison of CPB time and ACC between groups according to $P$-value

\begin{tabular}{ccc}
\hline Comparison between groups & CPB duration & ACC duration \\
Group 0-1 & 0.03 \\
Group 0-2 & 0.01 \\
Group 1-2 & 0.33 \\
\hline
\end{tabular}

CPB, cardiopulmonary bypass; ACC, aortic cross clamp.

Table 5. Early postoperative data of patients

\begin{tabular}{lccc}
\multicolumn{1}{c}{ Variables } & Group 1 $(n=60)$ & Group 2 $(n=60)$ & Group 0 ( $n=60)$ \\
\hline DMV, h & $13.9 \pm 10.5$ & $19.5 \pm 21.6$ & $11.7 \pm 7.24$ \\
Drenaj, cc & $903.3 \pm 506.7$ & $1024.5 \pm 582.4$ & $873.2 \pm 346.8$ \\
LSICU, days & $3.78 \pm 2.39$ & $4.85 \pm 3.42$ & $3.18 \pm 2.48$ \\
LSH, days & $8.20 \pm 3.02$ & $9.91 \pm 5.35$ & 0.59 \\
\hline
\end{tabular}

DMV, duration of mechanical ventilation; YBKS, length of stay in intensive care unit; LHS, length of stay in intensive care unit.

$\neq \mathrm{p}$-value is determined by the comparison of the three groups.

Risk scoring system for each patient was performed with the standard EuroSCORE. Risk analysis of the three groups was statistically significant (Table 2).

The patients' duration of diabetes was longer in patients with $\mathrm{HbA1c} \geq 7$ comparing with the patients with $\mathrm{HbA} 1 \mathrm{c}<7 \quad(\mathrm{P}<0.01)$.

Perioperative findings of the three groups are shown in Table 3. There was no significant difference between Group 1 and 2 , there was significant difference between the control group and group 1 and the control group and group 2 according to duration of CPB and aortic cross-clamping ACC of the patients (Table 4).

Out of 180 patients, 14 of them had to be reapplied CPB due to inadequate cardiac performance and intra-aortic balloon pump was used in these patients. Thirteen of these patients were diabetic patients.

Five $(8.3 \%)$ patients in the control group, $18(28.8 \%)$ patients in Group 1, and 21 (35\%) patients in Group 2 needed positive inotropic support. While there was a significant difference between the Control group and Group $1(P=0.03)$, and between the control group and Group $2(P<0.01)$, the difference between Group 1 and Group 2 ( $P=0.56$ ) was not significant.

\section{Postoperative findings}

The cumulative mortality rate was found to be $3.3 \%$. It was $1.7 \%$ in Group 1 with one patient and $8.3 \%$ in Group 2 with 5 patients. Mortality rates were significant in the comparison of all three groups $(P=0.01)$. The difference was not significant between the control group and Group $1(\mathrm{P}=0.31)$ and Group 1 and Group 2 $(P=0.09)$, there was significant difference statistically $(P=0.02)$ between the control group and Group 2.

Early postoperative morbidity and mortality data of patients are shown in Tables 5 and 6.

Group 2 was found to have a high rate of surgical site infections (Table 7).

In addition, acute deep vein thrombosis occured in three patients (two patients in the control group and one in group 2). Gastrointestinal bleeding In two patients (Group 2); pulmonary embolism in one patient (Group 2); achalasia in one patient (Group 1); paralytic ileus in two patients (Group 2) and significant hemolysis and thrombocytopenia in one patient (Group 2) were occured. 
Table 6. Morbidity and mortality data of patients

\begin{tabular}{|c|c|c|c|c|}
\hline Variables & Group $1(n=60)$ & Group $2(n=60)$ & Group $0(n=60)$ & $P$-value $\neq$ \\
\hline Revision, $\mathrm{n}(\%)$ & $7(11.7)$ & $6(10.0)$ & $2(3.3)$ & 0.18 \\
\hline Dialysis, n (\%) & $6(10.0)$ & $15(25.0)$ & 0 & $<0.01$ \\
\hline$A F, n(\%)$ & $14(23.3)$ & $20(33.3)$ & $8(13.3)$ & 0.01 \\
\hline CVA, n (\%) & $2(3.3)$ & $10(16.7)$ & $2(3.3)$ & 0.01 \\
\hline Surgical site infection, $n$ (\%) & $10(16.7)$ & $32(53.2)$ & $9(15.0)$ & $<0.01$ \\
\hline Mediastinitis, n (\%) & $5(8.3)$ & $7(11.7)$ & 0 & 0.01 \\
\hline Urinary infection, $\mathrm{n}(\%)$ & $4(6.7)$ & $6(10.0)$ & 0 & 0.01 \\
\hline Pneumonia, n (\%) & $6(10.0)$ & $6(6.0)$ & $2(3.3)$ & 0.17 \\
\hline Pleural effusion, n (\%) & $13(21.7)$ & $15(25.0)$ & $8(13.3)$ & 0.11 \\
\hline Sternal repair, n (\%) & $6(10.0)$ & $5(8.3)$ & $3(5.0)$ & 0.49 \\
\hline Mortality, n (\%) & $1(1.7)$ & $5(8.3)$ & 0 & 0.01 \\
\hline
\end{tabular}

$\mathrm{AF}$, atrial fibrillation; $\mathrm{CVA}$, cerebrovascular accident. $\neq \mathrm{p}$-value is determined by the comparison of the three groups

Table 7. Intergroup statistical rates of infection parameters

\begin{tabular}{lccc}
\hline Variables & \multicolumn{3}{c}{$P$-value } \\
& $0-1$ & $0-2$ & $1-2$ \\
\hline Surgical site infection & 0.80 & $<0.01$ & $<0.01$ \\
Mediastinitis & 0.02 & $<0.01$ & 0.54 \\
Urinary infection & 0.04 & 0.01 & 0.51 \\
Pneumonia & 0.14 & 0.14 & 1.00 \\
\hline
\end{tabular}

\section{Discussion}

The results of this study suggest that poor preoperative glycemic control ( $\mathrm{HbA} 1 \mathrm{C} \geq 7 \%$ ) is a predictor of morbidity after CABG in terms of cerebrovascular accident, surgical site infections, need for dyalisis, prolonged mechanical ventilation, prolonged hospital stay, reoperation for bleeding, and postoperative newonset AF. Cardiopulmonary bypass and aortic cross-clamp times were higher, use of positive inotropic drugs and intraaortic balloon pump (IABP) were more, intensive care unit (ICU) length of stay (LOS) and hospital LOS were longer in diabetics compared with non-diabetic patients after CABG.

The patients with diabetes have more advanced; diffuse coronary artery stenosis and more end-organ dysfunction, including renal insufficiency and neurologic deficits, and therefore clinicians who treat the diabetic patients with CAD should be aware of the effects this factor has on the outcomes of CABG surgery.

In a recent study consisting of 501 patients, it was reported that poor glycemic control (baseline HbA1c) prior to ischemic stroke is an independent risk factor for poor survival and a marker for increased stroke severity and unfavorable long-term functional outcome [6]. In this study, the CVA rate in postoperative patients with $\mathrm{HbA1C} \geq 7$ was significantly higher $(\mathrm{P}=0.01)$ than all other groups .

Knapik et al. [7] reported a retrospective review in 782 diabetic patients. For comparison of outcomes, patients were matched to achieve similar preoperative status with a use of a Greedy matching procedure. For matched patients elevated $\mathrm{HbA1c}$ levels $>7 \%$ were significantly associated with increased incidence of perioperative myocardial infarct (MI) compared with the HbA1c $<7 \%$ group $[4.7 \% \mathrm{HbA} 1 \mathrm{c}>7 \%,( \pm 95 \% \mathrm{Cl} \pm 3.18 \%)$ vs $0.6 \% \mathrm{HbA} 1 \mathrm{c}$ $\leq 7 \%$ ( $\pm 95 \% \mathrm{Cl} \pm 1.15 \%) ; \mathrm{P}=0.01$ ] (matched preoperative variables). There were no significant differences in all other morbidity, early mortality and total LOS $(P=0.59)$ including ICU $(P=0.94)$ in either HbA1c group.
In this study, it was found that unstable angina pectoris (USAP) was higher in diabetics $(P=0.02)$, especially in patients with $\mathrm{HbA1c}$ $\geq 7$ and the frequency of USAP was significantly higher compared to the other groups $(P<0.01)$. While the rate of myocardial infarction in diabetic patients appeared high, compared to with nondiabetics $(P=0.31)$, there was no significant difference. Diabetes mellitus is recognized as an independent risk factor for the development of atrial fibrillation (AF) [8]. Dublin and colleagues [8] have found higher rates of AF development in patients with DM and stated that the development of atrial fibrillation risk is related to $\mathrm{HbA} 1 \mathrm{c}$ levels.

Kinoshita et al. [9] also reported the association between $\mathrm{HbA} 1 \mathrm{c}$ levels and the development of postoperative atrial fibrillation. Interestingly, $\mathrm{HbA} 1 \mathrm{c}$ values were significantly lower in patients who developed AF postoperatively [HbA1c 5.8 (5.4-6.3) vs HbA1c 6.1 (5.5-7.2), P=0.01]. In this study, 7 of 12 patients who developed AF and did not restore sinus rhythm were in Group 2. The increased incidence of $A F$ in high $\mathrm{HbA1c}$ levels were found statistically significant $(P=0.01)$. The $H T$ ratio was higher in diabetic patients. We found significant correlation between increased $\mathrm{HbA1}$ c levels and the existence of $\mathrm{HT}(\mathrm{P}=0.01)$.

Schnack et al. [10] reported that pneumopathy incidence show correlation with $\mathrm{HbA1c}$ levels. In our study duration mechanical ventilation (MV) in non-diabetic patients was shorter. We have detected that MV periods prolonged as the $\mathrm{HbA1c}$ levels increased. We did not find significant differences among the three groups in terms of their bleeding after CABG surgery $(P=0.59)$. However, we also found increased bleeding amount as HbA1c levels and duration of diabetes increased. Postoperatively acute deep vein thrombosis occured in two patients with DM, pulmonary thromboembolism in one, and gastrointestinal bleeding in two, hemolysis and thrombocytopenia in one patient. All of these patients had higher $\mathrm{HbA1c}$ levels than $7 \%$.

It was shown that the diabetic patients had a higher incidence of infective complications [11, 12]. According to results of these studies, treatment of hyperglycemia in the postoperative period might reduce infection in the patients with DM [13]. Alserius et al. [14] conducted a prospective study correlating HbA1c concentrations with infection rate and mortality outcomes in 605 patients. Rates of superficial sternal wound infection were significantly increased in patients with $\mathrm{HbA1c} \geq 6 \%(13.9 \% \mathrm{HbA} 1 \mathrm{c}$ $\geq 6 \%$ vs $5.2 \%$ when $\mathrm{HbA} 1 \mathrm{c}<6 \%, \mathrm{P}=0.007)$. There was a trend towards higher rates of mediastinitis in $\mathrm{HbA} 1 \mathrm{c} \geq 6 \%$; however, these results were not significant $[4.9 \%$ in patients with $\mathrm{HbA} 1 \mathrm{c}$ $\geq 6 \%$ vs $2.1 \%$ in $\mathrm{HbA} 1 \mathrm{c}<6 \%$, hazard ratio (HR) $1.9,(95 \% \mathrm{Cl}$ : 0.6-5.9) 
$(P=0.20)]$. Mortality after 3 years was significantly higher in patients with $\mathrm{HbA} 1 \mathrm{c} \geq 6 \%$ after multivariable adjustment (all-cause mortality: $18.9 \%$ in $\mathrm{HbA} 1 \mathrm{c} \geq 6 \%$ vs $4.1 \%$ in $\mathrm{HbA} 1 \mathrm{c}<6 \%$, HR 5.4 (95\% $\mathrm{Cl}: 3-10)(\mathrm{P}<0.001)$.

In this study, it was found that there was a significant relationship between $\mathrm{HbA1c}$ levels and the development of infection among the patients who had coronary artery bypass surgery.

Some studies have pointed at diabetes as a risk factor for a poor outcome of operative mortality following CABG [15]. Similar to our findings, in some other studies, no significant relationship was found between diabetes and mortality $[16,17]$.

In a prospective study consisting of 3555 patients [3] it was reported that poor diabetic control is a significant indicator of post-CABG complications, and demonstrated a significant increase in the incidence of renal failure, infection, and length of hospital stay in patients with poorly (HbA1c $\geq 7$ ) controlled HbA1c preoperatively. An elevated $\mathrm{HbA1c}$ level increased the likelihood of hospital mortality after CABG (odds ratio 1.40 per unit increase, $\mathrm{p}=0.019$ ), with $\mathrm{HbA1c}>8.6 \%$ associated with a 4-fold increase in mortality. For each unit increase in $\mathrm{HbA1c}$, there was a significantly increased risk of myocardial infarction and deep sternal wound infection. Halkos et al. [18] also investigated longterm outcomes. Their results show a significant reduction in longterm survival (OR 1.15, $\mathrm{P}<0.001$ ) per unit increase in $\mathrm{HbA} 1 \mathrm{c} \geq 7 \%$. Selvin and colleagues [19] demonstrated that for every whole percentage increase in $\mathrm{HbA1c}$, the relative risk of cardiovascular disease increased by $18 \%$ for type 2 diabetes and by $15 \%$ for type 1 diabetes. Our study revealed no significant differences in hospital-mortality of CABG between $\mathrm{HbA} 1 \mathrm{c}<7$ and $\geq 7$ groups. This may be due to the fact that our study was conducted with fewer patients than above mentioned studies.

\section{Conclusion}

In our opinion, preoperative $\mathrm{HbA1c}$ level is a strong predictor of morbidity after CABG. In elective situations, it has been proposed that these patients should be delayed for surgery until adequate glycaemic control is achieved.

\section{Study limitations}

The main limitations of this study include its retrospective design with a limited number of participants. We have not studied the longterm outcomes, and it may be that although we are not seeing any difference in short-term outcomes, they may become apparent in the long term. The strengths of our study include presence of an adequate control group consisting of non-diabetic patients.

\section{Conflict of interest: none declared.}

\section{References}

1. Thourani VH, Weintraub WS, Stein B, Gebhart SS, Craver JM, Jones EL, et al. Influence of diabetes mellitus on early and late outcome after coronary artery bypass grafting. Ann Thorac Surg 1999; 67: 1045-1052 (PMID: 10320249)

2. Zhang $X, W u Z$, Peng $X$, Wu A, Yue $Y$, Martin J, et al. Prognosis of diabetic patients undergoing coronary artery bypass surgery compared with nondiabetics: a systematic review and meta analysis. J
Cardiothorac Vasc Anesth 2011; 25(2): 288-298. (PMID: 21147538) (doi: 10.1053/j.jvca.2010.09.021)

3. Halkos ME, Puskas JD, Lattouf OM, Kilgo P, Kerendi F, Song HK, et al. Elevated preoperative hemoglobin A1c level is predictive of adverse events after coronary artery bypass surgery. J Thorac Cardiovasc Surg 2008; 136(3): 631-640. (doi: 10.1016/j.jtcvs.2008.02.091) (PMID: 18805264)

4. Tennyson $\mathrm{C}$, Lee $\mathrm{R}$, Attia $\mathrm{R}$. Is there a role for $\mathrm{HbA1c}$ in predicting mortality and morbidity outcomes after coronary artery bypass graft surgery? Interact Cardiovasc Thorac Surg 2013; 17(6): 1000-1008. (doi: 10.1093/icvts/ivt351) (PMID: 24021615)

5. Jessen ME. Glucose control during cardiac surgery: How sweet it is. $J$ Thorac Cardiovasc Surg 2003; 125(5): 985-987. (PMID: 12771868)

6. Hjalmarsson C, Manhem K, Bokemark L, Andersson B. The role of prestroke glycemic control on severity and outcome of acute ischemic stroke. Res Treat 2014; 2014: 694569. (doi: 10.1155/2014/694569) (PMID: 25295219)

7. Knapik P, Ciesla D, Filipiak K, Knapik M, Zembala M. Prevalence and clinical significance of elevated preoperative glycosylated hemoglobin in diabetic patients scheduled for coronary artery surgery. Eur J Cardiothorac Surg 2011; 39(4): 484-489. (PMID: 21087870) (doi: 10.1016/j.ejcts.2010.07.037)

8. Dublin S, Glazer NL, Smith NL, Psaty BM, Lumley T, Wiggins KL, et al. Diabetes mellitus, glycemic control, and risk of atrial fibrillation. J Gen Intern Med 2010; 25(8): 853-858. (doi: 10.1007/s11606-010-1340-y) (PMID: 20405332)

9. Kinoshita T, Asai T, Suzuki T, Kambara A, Matsubayashi K. Preoperative hemoglobin A1c predicts atrial fibrillation after off-pump coronary artery bypass surgery. Eur J Cardiothorac Surg 2012; 41(1): 102-107. (doi: 10.1016/j.ejcts.2011.04.011) (PMID:21612941)

10. Schnack C, Festa A, Schwarzmaier-D'Assié A, Haber P, Schernthaner G. Pulmonary dysfunction in type 1 diabetes in relation to metabolic longterm control and to incipient diabetic nephropathy. Nephron 1996; 74 : 395-400. (PMID: 8893162)

11. Farsky PS, Graner H, Duccini P, Zandonadi Eda C, Amato VL, Anger J, Sanches AF, Abboud CS. Risk factors for sternal wound infections and application of the STS score in coronary artery bypass graft surgery. Rev Bras Cir Cardiovasc 2011; 26(4): 624-629. (PMID: 22358279)

12. Lola I, Levidiotou S, Petrou A, Arnaoutoglou H, Apostolakis E, Papadopoulos GS. Are there independent predisposing factors for postoperative infections following open heart surgery? J Cardiothorac Surg 2011; 6: 151. (doi: 10.1186/1749-8090-6-151) (PMID: 22082355)

13. Filho EM, de Carvalho WB, Cavalheiro S, Horigoshi NK, Freddi NA, Vieira GK, et al. Hyperglycemia predicts mortality after CABG: postoperative hyperglycemia predicts dramatic increases in mortality after coronary artery bypass graft surgery. Clinics (Sao Paulo) 2011; 66(9): 1637-1640. (doi: 10.1590/S1807-59322011000900022)

14. Alserius $T$, Anderson R, Hammar N, Nordqvist T, Ivert T. Elevated glycosylated haemoglobin ( $\mathrm{HbA} 1 \mathrm{c}$ ) is a risk marker in coronary artery bypass surgery. Scand Cardiovasc J 2008; 42(6): 392-398. (doi: 10.1080/14017430801942393) (PMID: 18609043)

15. Kubal C, Srinivasan AK, Grayson AD, Fabri BM, Chalmers JA. Effect of risk-adjusted diabetes on mortality and morbidity after coronary artery bypass surgery. Ann Thorac Surg 2005; 79(5): 1570-1576. (PMID: 15854935)

16. Brandt $M$, Harder K, Walluscheck KP, Fraund S, Böning A, Cremer J. Coronary artery bypass surgery in diabetic patients. J Card Surg 2004; 19(1): 36-40. (PMID: 15108787)

17. Moshtaghi N, Shirzad M, Karimi A, Ahmadi H, Marzban M, Abbasi K, et al. Outcome of coronary artery bypass surgery in diabetic and nondiabetic patients: A comparative, retrospective study. Journal of Diabetology 2010; 3: 2.

18. Halkos M, Lattouf O, Puskas J, Kilgo P, Cooper W, Morris C, et al. Elevated preoperative hemoglobin $\mathrm{A} 1 \mathrm{c}$ level is associated with reduced long-term survival after artery bypass surgery. Ann Thorac 
Surg 2008; 86(5): 1431-1437. (doi: 10.1016/j.athoracsur.2008.06.078) (PMID: 19049726)

19. Selvin E, Marinopoulos S, Berkenblit G, Rami T, Brancati FL, Powe NR, et al. Meta-analysis: glycosylated hemoglobin and cardiovascular disease in diabetes mellitus. Ann Intern Med 2004; 141(6): 421-431. (PMID: 15381515)

Authors:

Ümit Arslan - MD, Senior researcher, Department of Cardiovascular Surgery, Atatürk Training and Education Hospital, Erzurum, Turkey.

Mehmet Erdem Memetoğlu - MD, Senior researcher, Department of Cardiovascular Surgery, Dr.Siyami Ersek Cardiovascular and Thoracic Surgery Hospital, İstanbul, Turkey.

Rasim Kutlu - Associate Professor, Department of Cardiology, Denizli State Hospital, Denizli, Turkey.

Ozan Erbasan - MD, Senior researcher, Department of Cardiovascular Surgery, Akdeniz University School of Medicine, Antalya, Turkey.

Mehmet Tort - Senior researcher, Department of Cardiovascular Surgery, Atatürk Training and Education Hospital, Erzurum, Turkey.

Eyüp Serhat Çalık - Senior researcher, Department of Cardiovascular Surgery, Atatürk Training and Education Hospital, Erzurum, Turkey.

Ziya Yıldız - Senior researcher, Department of Cardiovascular Surgery, Atatürk Training and Education Hospital, Erzurum, Turkey.

M. Ali Kaygın - Senior researcher, Department of Cardiovascular Surgery, Atatürk Training and Education Hospital, Erzurum, Turkey.

Ozan Erdem - MD, Senior researcher, Department of Cardiovascular Surgery, Akdeniz University School of Medicine, Antalya, Turkey.

Ali İhsan Tekin - MD, Senior researcher, Department of Cardiovascular Surgery, Akdeniz University School of Medicine, Antalya, Turkey. 